\title{
PENGARUH BAHAN DIELEKTRIK DALAM UNJUK KERJA WAVEGUIDE
}

\author{
Lince Markis \\ Jurusan Teknik Elektro Politeknik Negeri Padang \\ Kampus Unand Limau Manis Padang \\ E-mail: lincemarkis@yahoo.com
}

\begin{abstract}
ABSTRAK
Makalah ini menyajikan hasil studi pengukuran nilai Voltage Standing Wave Ratio (VSWR) dan power reflection factor (PRF) untuk berbagai jenis bahan dielektrik yang akan disisipkan pada saluran transmisi yang beroperasi di frekuensi $9 \mathrm{GH}$ dan dibandingkan dengan saluran transmisi tanpa bahan dielektrik. Pengukuran dilakukan di laboratorium antena Politeknik Negeri Padang dengan menggunakan alat ukur penunjang komponen waveguide yang berfungsi menghasilkan nilai VSWR dan PRF sehingga didapatkan grafik gelombang berdiri dengan parameter tegangan dan jarak. Pengukuran dilakukan dengan menjadikan bahan dielektrik berbagai jenis dengan kondisi rangkaian terbuka. Pengukuran pertama dilakukan untuk bahan dielektrik jenis teflon berwarna putih diperoleh hasil VSWR sebesar 28,50 dengan PRF 86,90\% sedangakan bahan dielektrik jenis plexiglass berwarna transparan nilai VSWR sebesar 12,39 PRF 72,35 \% dan bahan dielektrik jenis PVC berwarna abu-abu VSWR 7,97 dengan PRF 60,39 \%. Sedangkan untuk saluran transmisi tanpa bahan dielektrik ( tidak disisipi bahan dielektrik ) nilai VSWR 1,50 dengan PRF $4,01 \%$.
\end{abstract}

Kata kunci: Wavequide, bahan dielektrik, standing wave ratio, power reflection factor, microwaves

\section{PENDAHULUAN}

Berbagai jenis bahan dielektrik yang digunakan didalam pemandu gelombang seperti teflon, PVC dan plexiglass dioperasikan dalam saluran transmisi pada frekuensi $9 \mathrm{GHz}$. Bahan-bahan dielektrik tersebut digunakan dalam menyelesaikan kegiatan ini. Selain itu dalam kegiatan ini akan dibandingkan hasil Voltage Standing Wave Ratio (VSWR) dan Power Reflection Factor (PRF) dari rangkaian pemandu gelombang yang disisipi bahan dielektrik dengan rangkaian tanpa bahan dielektrik untuk kondisi rangkaian terbuka. Kegiatan ini dilakukan dilaboratorium antena Politeknik Negeri Padang. Didalam kegiatan pengukuran yang dilakukan menggunakan peralatan penunjang yang ada di laboratorium antena program studi telekomunikasi.

Penggunaan peralatan Unitrain ini sangat menunjang dalam pengukuran nilai VSWR dan PRF. Pengukuran ini dilakukan menggunakan slotted line dengan panjang $7 \mathrm{~cm}$. Pengukuran disepanjang slotted line dilakukan dengan cara menggeser. Hasil pengukuran ini menghasilkan nilai VSWR dan PRF serta grafik nilai tegangan terhadap jarak yang nantinya merupakan nilai tegangan maksimum dan tegangan minimum.

\section{TINJAUAN PUSTAKA}

Pemandu Gelombang Segi Empat (Rectangular Waveguide)

Pemandu gelombang adalah saluran transmisi yang berperan penting dalam transmisi gelombang frekuensi tinggi. Dimensi pemandu gelombang secara umum mempunyai ukuran yang besar kearah tiga dimensi. Pada pemandu gelombang segi empat ada dua mode utama yaitu mode $\mathrm{H}$ yang merupakan gelombang tranversal elektris dan mode $\mathrm{E}$ yang merupakan gelombang tranversal magnetis. Pada gambar 1 . terlihat geometri 
pemandu gelombang segi empat. Gelombang transversal merujuk kepada arah z yang merupakan panjang pemandu gelombang. pada sisi kiri dan kanan penghantar, di $\mathrm{x}=0$ atau $\mathrm{x}=$ a yang merupakan lebar pemandu gelombang dan disisi atas dan bawah penghantar, di $\mathrm{y}=0$ atau $\mathrm{y}=\mathrm{b}$, yang menyatakan tinggi pemandu gelombang. Pada kasus pemandu gelombang diasumsikan pemandu gelombang terbuat dari bahan penghantar ideal. Medan listrik tidak boleh mempunyai komponen tangen $\left(\mathrm{E}_{\mathrm{tan}}=0\right)$ dan medan magnet tidak boleh mempunyai komponen normal $\left(\mathrm{H}_{\mathrm{n}}=0\right)$.

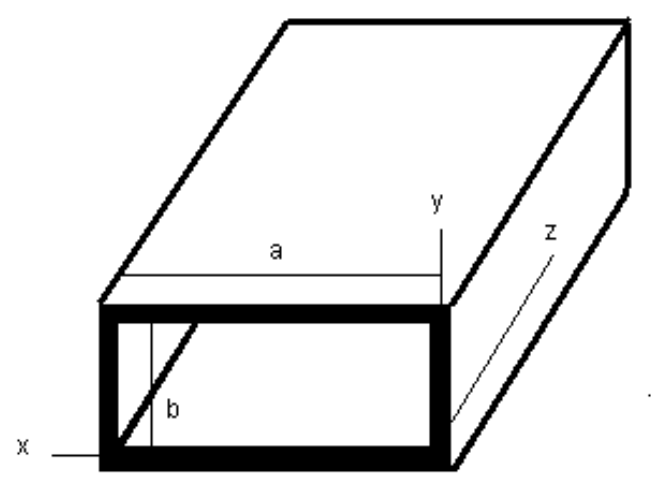

Gambar 1. Geometri pandu gelombang segi empat

Jika frekuensi sinyal lebih kecil dari frekuensi cut-off $\left(f_{c}\right)$ maka sinyal tak akan merambat. Namun jika frekuensi sinyal lebih tinggi dari $f_{c}$ maka akan merambat beberapa mode.

\section{Pantulan Gelombang}

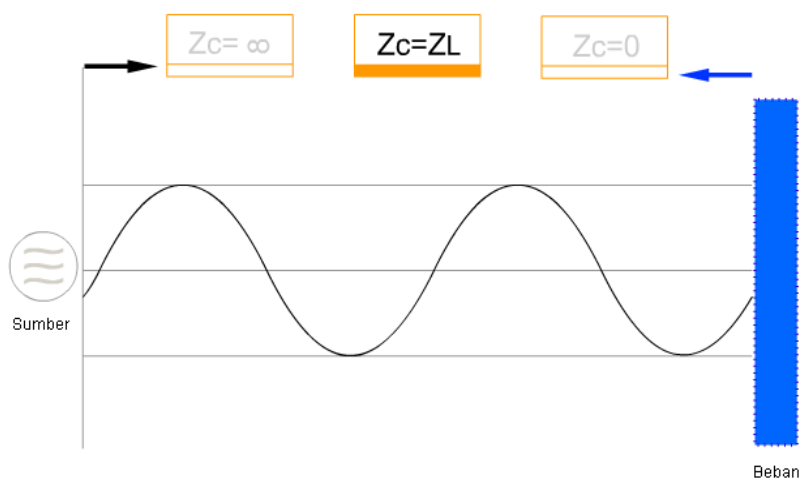

Gambar. 2 Gelombang saat $\mathrm{Z}_{\mathrm{C}}$ sama $\mathrm{Z}_{\mathrm{L}}$

Pada gambar 2 menjelaskan gelombang yang berasal dari sumber ke beban tidak mengalami pantulan atan tidak berbalok arah dari beban ke sumber sehingga kondisi pada saat $\mathrm{Z}_{\mathrm{C}}=\mathrm{Z}_{\mathrm{L}}$ tersebut memiliki amplitudo konstan. 


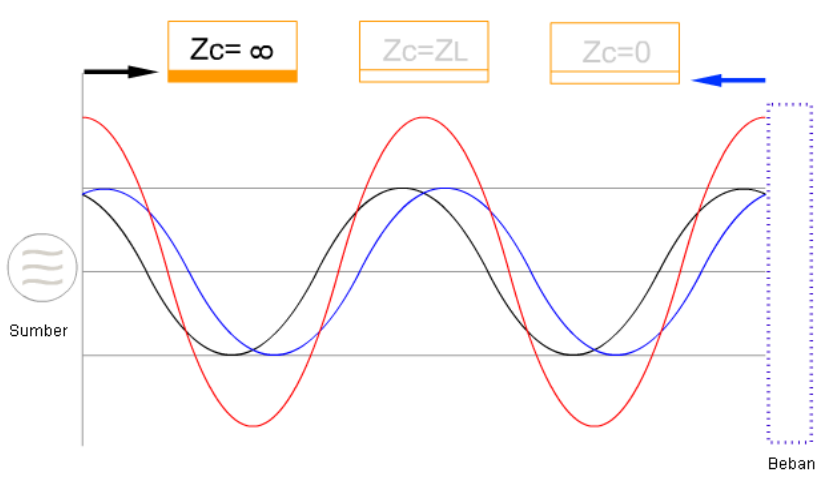

Gambar 3. Gelombang saat $\mathrm{Z}_{\mathrm{C}}$ sama

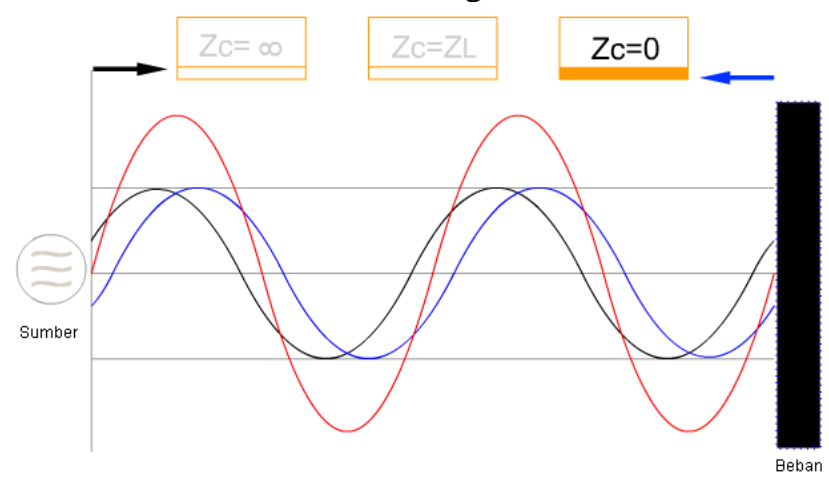

Gambar 4. Gelombang saat ZC sama nol

Gambar 3 dan 4 menjelaskan adanya gelombang yang dipantulkan kembali kearah sumber. Sehingga dihasilkan amplitudo gelombang yang bervariasi artinya terjadi gelombang berdiri.

Gelombang dalam saluran transmisi merambat dimulai dari sumber ke beban dan dipantulkan (reflection) pada ujungnya. Reflectio factor (r) dapat dirumuskan :

$$
\mathrm{r}=\mathrm{Z}_{\mathrm{L}}-\mathrm{Z}_{0} / \mathrm{Z}_{\mathrm{L}}+\mathrm{Z}_{0}
$$

Reflection factor dapat bernilai komplek tetapi untuk beban yang bersifat pasif nilai magnitudonya adalah $|\mathrm{r}| \leq 1$.

\section{Bahan Dielektrik}

Propagasi dari gelombang elektromaknetik didalam bahan dielektrik memiliki $\varepsilon_{r}$ sangat lambat sebesar factor $\sqrt{\varepsilon_{r}}$ dibandingkan propagasi di udara atau ruang hampa udara. Panjang gelombang akan berubah sesuai dengan faktor yang sama. Mengacu pada propagasi gelombang dalam ruang bebas, frekuensi cut-off untuk pemandu gelombang $\lambda_{c}$ perlu dipertimbangkan. Kondisi ini seperti pada persamaan berikut ini :

$$
2 \mathrm{a} \equiv \lambda_{\mathrm{c}}
$$

Pengukuran panjang gelombang $\lambda_{z \varepsilon}$ dilakukan ketika waveguide diisi bahan dielektrik. Untuk panjang gelombang $\lambda_{0 \varepsilon}$ tanpa bahan dielektrik didalamnya maka perlu dihitung ulang dengan menggunakan persamaan propagasi gelombang dalam pemandu gelombang.

$$
\lambda_{o \varepsilon}^{2}=\frac{\lambda_{z \varepsilon}^{2} \cdot \lambda_{c}^{2}}{\lambda_{z \varepsilon}^{2}+\lambda_{c}^{2}}
$$


Menghitung kuadrat dari panjang gelombang di ruang bebas $\lambda_{0}$ untuk setiap bahan dielektrik dari panjang gelombang yang diukur dari rumus di atas. Nilai untuk permitivitas relatif $\varepsilon_{\mathrm{r}}$ adalah :

$$
\varepsilon_{r}=\frac{\lambda_{o}^{2}}{\lambda_{0 \varepsilon}^{2}}
$$

\section{Standing Wave Rasio (SWR)}

Standing wave (gelombang berdiri) disebabkan oleh adanya gelombang berjalan pada arah yang berlawanan dalam suatu saluran transmisi. Rasio dari gelombang berdiri maksimum terhadap minimumnya didefinisikan sebagai standing wave ratio (SWR).

$$
\mathrm{SWR}=\mathrm{V}_{\text {max }} / \mathrm{V}_{\text {min }}
$$

Karena SWR untuk tegangan dan arus adalah sama, maka tidak ada perbedaan antara VSWR dan ISWR.

Standing wave ratio disebabkan oleh kenyataan bahwa dua komponen gelombang berjalan saling menjumlahkan (sephase) pada beberapa titik dan saling melemahkan di titik yang lain. Jarak antara dua maksimum atau minimum.

Jika SWR bernilai satu, berarti tidak ada gelombang pantul. SWR tidak bisa didefinisikan pada saluran transmisi dengan rugi-rugi (lossy), karena pola gelombang berdiri berubahubah antara satu posisi dengan posisi lainnya. Untuk saluran dengan rugi-rugi kecil, rasio relatif konstan dan masih bisa didefinisikan.

\section{METODE PENELITIAN}

Untuk melaksanakan kegiatan ini telah ditempuh berdasarkan langkah-langkah sebagai berikut :

1. Studi tentang penggunaan bahan dielektrik didalam saluran transmisi pada frekuensi gelombang mikro.

2. Perakitan peralatan dan komponen pemandu gelombang yang digunakan dalam melakukan pengukuran.

3. Pengesetan nilai -nilai atau parameter yang digunakan dalam menunjang pengukuran.

4. Pengukuran nilai VSWR dan koefisien refleksi daya menggunakan peralatan Lucas Nulle dan mendapatkan grafik pengukuran.

5. Pengambilan data berupa nilai dan grafik dari beberapa jenis bahan dielektrik dan tanpa bahan dielektrik yang digunakan pada frekuensi $9 \mathrm{GHz}$ untuk rangkaian terbuka.

Adapun modul-modul dan peralatan penunjang yang digunakan dalam kegiatan ini adalah:

1. Modul Unitrain produksi Lucas Nulle

2. Modul Lucas Nulle L@Bsoft

3. Bahan dielektrik Teflon, Plexiglass dan PVC.

4. Komponen pemandu gelombang penunjang seperti Gunn Oscilator SO4100-4A, Isolator SO4100-4B, Slotted line SO4100-4F, Displacemen Sensor for Slotted Line SO4100-4S. 


\section{HASIL DAN PEMBAHASAN}

Hasil yang sudah dicapai pada kegiatan ini adalah :

1. Berupa nilai VSWR dan koefisien refleksi daya serta grafik hasil pengukuran sepanjang saluran transmisi $7 \mathrm{~mm}$ menggunakan slotted line.

2. Data berupa analisis untuk berbagai jenis bahan dielektrik yang digunakan dalam eksperimen ini.

3. Hasil pengukuran untuk jenis bahan dielektrik yang berbeda.

4. Hasil pengukuran untuk saluran transmisi yang tidak disisipi bahan dielektrik (bahan dielektrik udara).

5. Perbandingan hasil pengukuran antara saluran transmisi yang disisipi bahan dielektrik dengan tanpa bahan dielektrik.

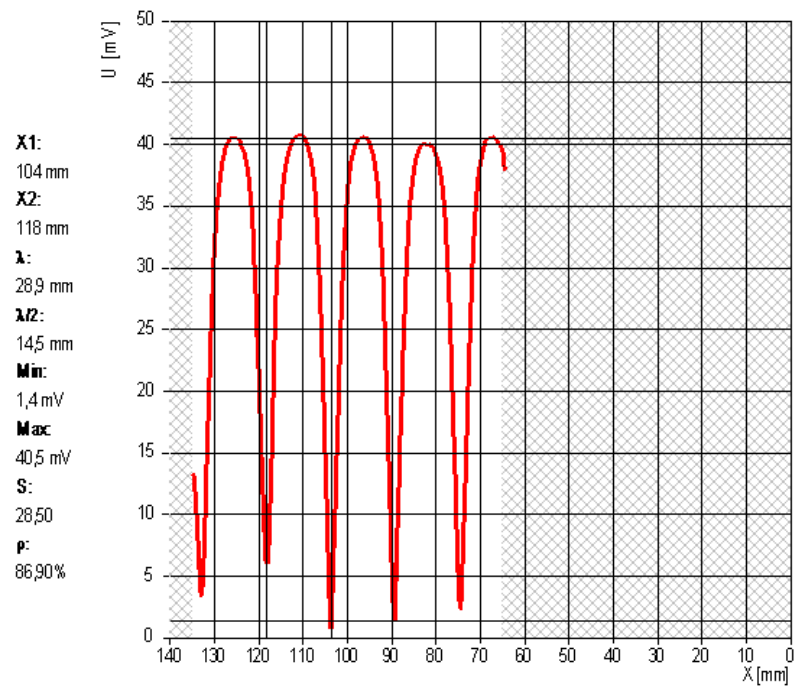

Gambar 5. Grafik hubungan panjang saluran transmisi $(\mathrm{mm})$ dan nilai tegangan $(\mathrm{mV})$ pada wave guide dengan bahan dielektrik Teflon ( putih )

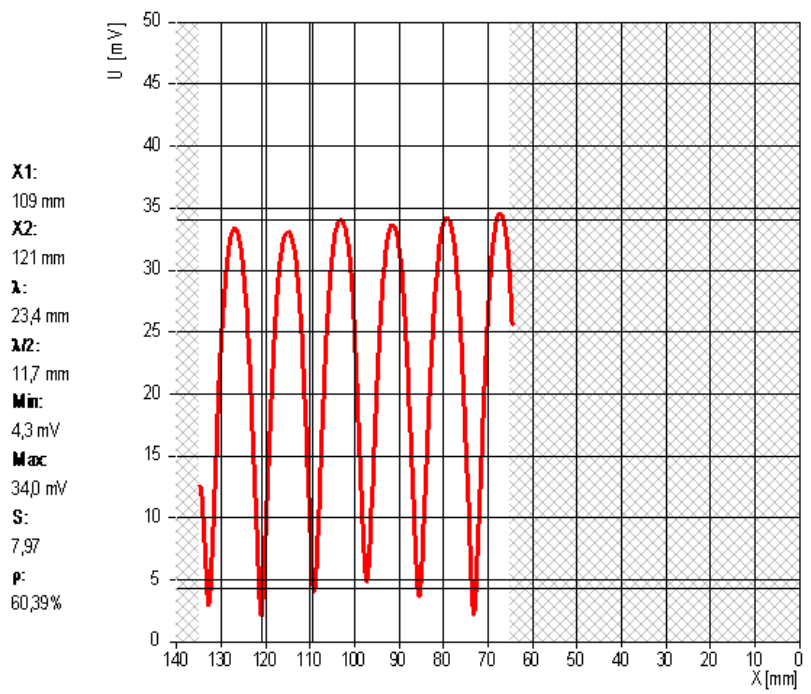

Gambar 6. Grafik hubungan panjang saluran transmisi $(\mathrm{mm})$ dan nilai tegangan $(\mathrm{mV})$ pada wave guide dengan bahan dielektrik PVC ( abu-abu ) 


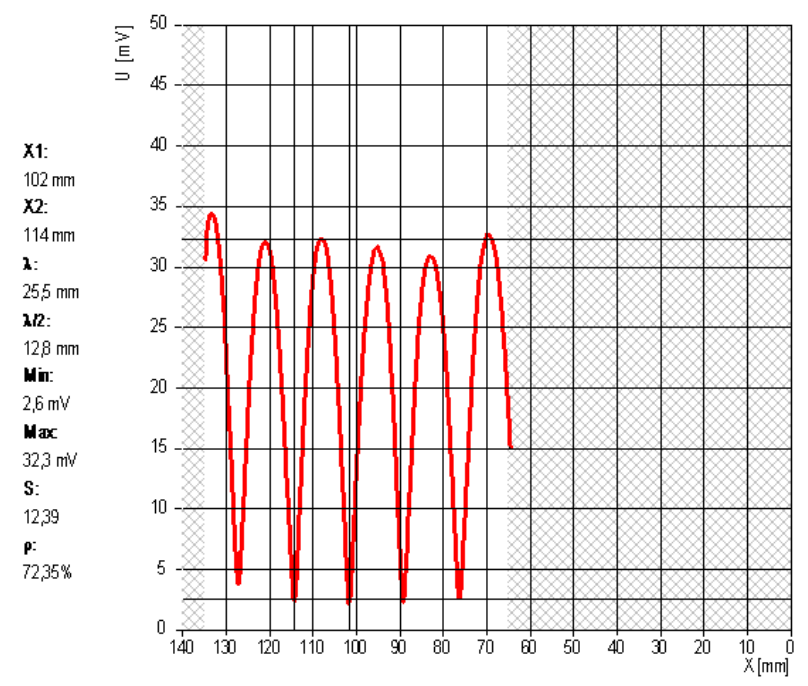

Gambar 7. Grafik hubungan panjang saluran transmisi (mm) dan nilai tegangan (mV) pada wave guide dengan bahan dielektrik Plexiglass ( transparan )

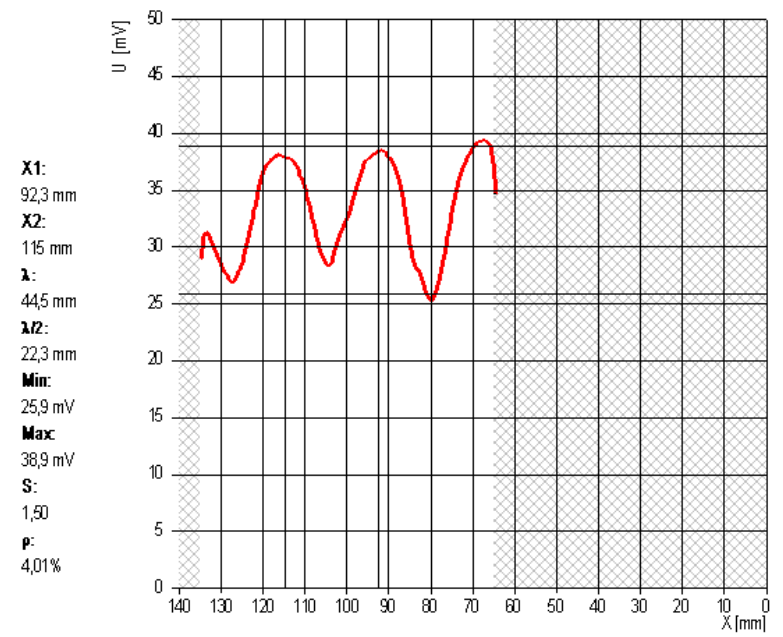

Gambar 8. Grafik hubungan panjang saluran transmisi ( $\mathrm{mm})$ dan nilai tegangan $(\mathrm{mV})$ pada wave guide tanpa bahan dielektrik

Hasil pengukuran pada gambar 5,6,7 dan 8 menunjukan nilai VSWR dan PRF untuk setiap jenis bahan dielektrik. Grafik menyatakan nilai tegangan dalam arah vertikal dan panjang saluran transmisi diwakili dalam arah horizontal. Besaran yang dihasilkan dari grafik terlihat nilai $\mathrm{x}_{1}$ dan $\mathrm{x}_{2}$ yang mewakili jarak dari 2 puncak gelombang yang menyatakan nilai panjang gelombang. Nilai VSWR terwakili dengan nilai max dan min. VSWR diwakili dengan simbol S dan PRF terwakili dengan simbol $\rho$.

Pada kegiatan pengukuran untuk berbagai macam jenis bahan dielektrik pada frekuensi 9 $\mathrm{GHz}$ yang diletakan didalam saluran transmisi. Jenis bahan dielektrik teflon memiliki warna putih, Plexiglass memiliki warna transparan dan PVC berwarna abu-abu. Hasil pengukuran untuk setiap jenis bahan dielektrik tersebut dibandingkan dengan saluran transmisi yang tidak disisipi bahan dielektrik . Pengukuran ini dilakukan untuk rangkaian dalam kondisi terbuka. Gambar 9 merupakan komponen waveguide dalam menunjang pengukuran. 


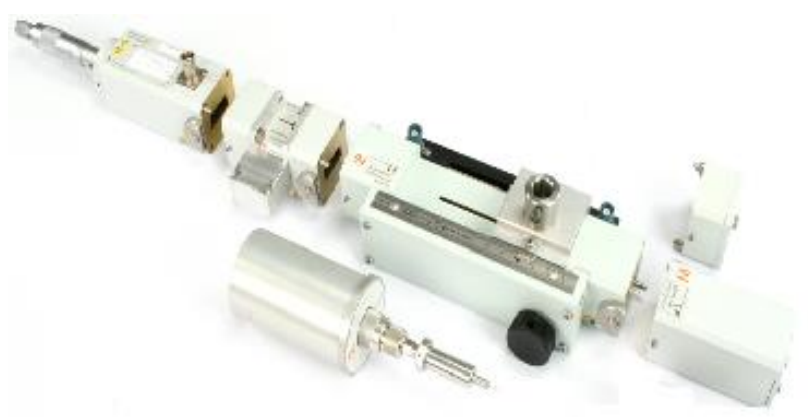

Gambar 9. Komponen penunjang pengukuran

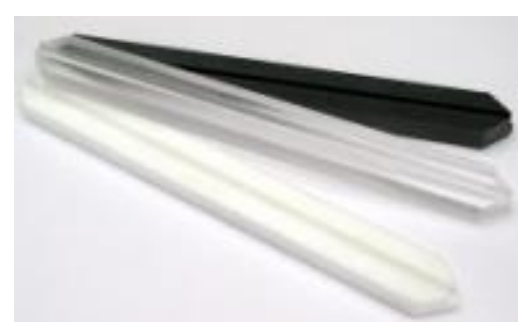

Gambar 10. Bahan dielektrik

Gambar 10 merupakan jenis bahan dielektrik yang digunakan didalam saluran transmisi untuk pengukuran. Percobaan dilakukan dengan cara merakit komponen waveguide dan peralatan penunjang dalam pengukuran.

Dengan selesainya kegiatan ini yang menghasilkan data dan analisis mengenai penerapan berbagai macam jenis bahan dielektrik pada frekuensi $9 \mathrm{GHz}$ yang diterapkan di saluran transmisi.

Hasil pengukuran nilai VSWR dan PRF berturut-turut untuk beberapa jenis bahan dielektrik teflon, plexiglass dan PVC adalah 28,50:86,90\%, 12,39: 72,35\% , 7,97: 60,39\%. Hasil pengukuran nilai VSWR dan PRF tanpa bahan dielektrik adalah 1,50 : $4,01 \%$. Artinya saluran transmisi dengan bahan dielektrik memiliki VSWR dan PRF yang lebih besar dibandingkan tanpa bahan dielektrik. Dengan saluran transmisi tanpa bahan dielektrik memiliki kualitas yang lebih baik.

\section{KESIMPULAN}

Hasil pengukuran nilai VSWR dan PRF dalam saluran transmisi tanpa bahan dielektrik lebih kecil dibandingkan dengan menggunakan bahan dielektrik.

\section{DAFTAR PUSTAKA}

1. Balanis, Antenna Theory 2nd Edition, 1997.

2. Balanis, Microwave Antenna Theory and Design, 1997.

3. Mudrik Alaydrus, Saluran Transmisi Telekomunikasi, Graha Ilmu, 2009.

4. Simon R. Saunders, Antennas And Propagation, John Willey \& Sons LTD, England, 1999.

5. Unitrain,LucasNulleL@bsoft, Germany, 2008. 